\title{
Construct Validity and Transpositional Research : Toward an Empirical Study of Psychoanalytic Concepts
}

\author{
By Alexander Z. Guiora
}

$\mathbf{L}$ IKE ALL GREAT HOUSES, the magnificent edifice of psychological constructs, erected by the master-architect Sigmund Freud has a resident ghost. This ghost is the spirit of verification.

The imposing structure of psychoanalytic concepts has, of course, considerable internal consistency and coherence. This, otherwise felicitous circumstance however, further complicates the situation by frequently leading to substitution of fraternal concurrence for construct validity. The following quotation from Heinz Hartmann will illustrate my point.

In this (analytic) setting, data do appear which are not, or not easily, accessible to other methods. This asset as to factfinding has of course, a disadvantage in another respect: an observation an analyst makes may seem entirely credible to another analyst who possesses the necessary experience, an interpretation quite convincing, while the same observation may appear hardly credible, the same interpretation highly improbable or artificial, to one who approaches the field with a different method and in a different setting. ${ }^{18}$

It is the responsibility of those who seek to understand and to explain to others human behavior in its infinite complexity yet essential lawfulness, to make the fruits of their labor public, demonstrable, and accessible to all. The pursuit of knowledge, by whatever method, cannot remain private. Its results and the ways those results were obtained have to be made public. It may not be possible to articulate the process of the occasional exhilirating creative flash, but it is imperative that the insights thus gained be scrutinized in the cold daylight of systematic verification. Otherwise the pursuit of knowledge becomes a system of beliefs, an arcane faith, and outside the pale of science.

In a previous communication, I have argued for the necessity of submitting hypotheses based on clinical observations to "a systematic critical examination that will yield lawful relationships between the observed phenomena, reliable and valid predictions about future events and the results of which lend themselves to public scrutiny". ${ }^{13}$

There are, however, many methodological hurdles to clear in any attempt to abide by the above exhortation, because clinical observations and psychoanalytic hypotheses developed from them, are, more often than not, expressed in constructs and not in denotative terms unequivocally describing real events and objects. The following passage will illustrate the point. "And as the obsessional neurotic reverses against himself the unconscious aggression originally directed against his father, so the Jewish people turn against themselves the hostility they originally experienced toward God and toward their conquerors." 24 A number of statements are made in this quotation, some

From the Departments of Psychiatry and Psychology, The-University of Michigan, Ann Arbor, Mich.

Alexander Z. Guiora, Ph. D.: Professor of Psychology, Departments of Psychiatry and Psychology, The University of Michigan, Ann Arbor, Mich. 
of them explicitly, others implicitly, that should be submitted to a "systematic and critical examination" before any validity can be claimed for them.

The first such statement is "obsessional neurotic." Granted that the category "obsessional neurotic" can be unequivocally described and rendered denotative (a methodological largesse not entirely warranted by facts, but permissible in the exercise). The next cluster of statements, however, "reverses against himself the unconscious aggression originally directed against his father" contains at least three bold assertions, assuredly based on painstaking clinical observations, but nevertheless devoid of an unequivocal denotative meaning. Let us examine this condition more closely. In the statement "the neurotic reverses against himself" an action is suggested; denotative particulars, however, are not furnished. It is to be assumed that the expression "reverses against himself" is an interpretation rather than description of an act or acts; in other words, a connotative construction placed on certain behaviors, a higher than first level inference, in short, a psychological construct. Difficult as it might prove to be to submit that construct to a "systematic and critical examination," we will be in even greater difficulty in our attempts to achieve the same for the next statement, "unconscious aggression." Here we are dealing with a higher level of inference than before; our construct is becoming less and less denotative and more and more removed from unequivocal description of real events and objects. If "unconscious aggression" is difficult, "the Jewish people turn against themselves the hostility they originally experienced toward God" creates a well-nigh insurmountable methodological problem.

I have come to distinguish between different levels of inference by dividing them into two broad categories: "high constructs" and "low constructs," respectively. A low construct is defined as a postulated psychic phenomenon or process whose existence is not verifiable on the basis of observable overt behavior, but once illustrated it becomes plausible because predicted events can readily be derived from it, e.g., the process of inference or logical (Aristotelian) deduction/induction. A high construct is defined as a postulated psychic phenomenon or process, whose existence is not verifiable on the basis of observable overt behavior, nor can it become plausible through illustration, because predicted events cannot readily be derived from it; e.g., the process of empathy or the process of intuition.

My own interest in the clinical process and in the comprehending modalities characteristic of it has led to an almust exclusive preoccupation with high constructs. In an attempt to meet the methodological requirements posited earlier, I have proposed a research strategy that I termed "transpositional." In the paper first describing this new research strategy, I wrote:

The question of methodology, or appropriate methodologies, has pursued in many ways the psychological sciences from their very beginnings. There are obvious difficulties. The scientific method, so critical and fruitful to the development of Western civilization cannot be applied automatically without modifying it, to our data, to the clinical circumstance. This recognition led to varied and, at times, surprising if not always fruitful responses.

On the one extreme it was suggested that if our data do not fit the scientific method, then they are bad data and are outside the realm of scientific inquiry. A corollary and equally extreme position is that if the scientific method does not fit our data, then the scientific method has to be abandoned. Thus an easy and angry dichotomy has been created between the "scientists" and the "practitioners" in the field, neither contributing to nor influencing the other. A dialogue of the deaf ensued, the only comprehensible sounds of which are mutual recriminations and disparagements.

Between these two extreme positions we find a number of attempts to bridge the gap 
between clinical data and the ill-fitting scientific method. These attempts fall essentially into two categories: reductionist and analogue research.

Reductionism, briefly stated, is an attempt to operationalize the hypothesis generated in the clinical situation so that it lends itself to empirical investigation. The obvious hazard lies in reducing the original question too much so that the ensuing result will border on the trivial. Psychological journals are full of this kind of well-intended exercise in futility.

Analogue research as a strategy recognizes the liabilities of extreme reductionism and attempts to create an assumed analogue to the original clinical circumstance. ... This approach is more promising than the different shades of reductionism but it has its obvious limitations as to the "realness" of the laboratory situation and as to the meaningfulness of the findings.

In reflection, it seems to me that clinical research implies a systematic attempt to gain knowledge about human functioning, in circumstances usually significantly different from those of the laboratory. The nature of the clinical setting imposes limits on the freedom of data collection and manipulation of subject population. Clinical research strategies must be adapted to available, natural sources of information, whereas data collection in most laboratory research can follow the dictates of controlled best design. Further, the subjects of clinical psychological research are, more likely than not, apt to be people in plain, who approach every procedure and intervention with conscious or unconscious expectations and apprehensions and whose integrity and human dignity take unconditional procedure over experimental needs and procedures. 13

The research strategy that we came to rely on in our own work can be described as follows: in face of the built-in liabilities of the reductionist and analogue research we have abandoned attempts to achieve better operationalizations. Instead of that we try to identify another realm of behavior, where the phenomena, first observed in the clinical situation, can be assumed also to exist. That other realm of behavior however, in contradistinction to the original clinical circumstance, is of such a nature that it lends itself readily to manipulation of variables and populations, to rigorous empirical research. I call this strategy transpositional research.

My current efforts in the study of certain high constructs such as empathy, or flexibility of psychic processes, in general, can serve as an illustration of this new approach.

The task of defining the process of empathy is difficult. This is clearly reflected in the wide divergence of description which a survey of the relevant literation reveals concerning the nature of empathy. Freud referred to empathy as being "... the mechanism by means of which we are enabled to take up any attitude at all toward another mental life." ${ }^{8}$ For Fenichel ${ }^{6}$ empathy involves both an identification with another person and an awareness of one's own feelings after the identification; in this way, awareness of the feelings of the object identified with becomes possible. Reik ${ }^{30}$ noted that, "What is essential in the psychical process going on is-after the stage of observation-that (the observer) can vibrate unconsciously in the rhythm of the other person's impulse and yet be capable of grasping it as something outside himself and comprehending it psychologically, sharing the other's experience and yet remaining above the struggle...."11 Schafer ${ }^{33}$ writes, "Generative empathy may be defined as the inner experience at sharing in and comprehending the momentary psychological state of another person... . This is unlike the actor's narcissistic appropriation of the characteristics of others; it is also unlike the schizophrenic's confusion as to where he leaves off and the other person begins." Each of these descriptions, to some degree, touches upon a particular kind of shared relationship between person and object.

The element of sharing, of gaining understanding through some kind of intimate relationship, seems to be an essential aspect of the empathic act. This sharing implies more than mere recognition of another's feelings or a relationship based on identification per se. Thus, Katz ${ }^{20}$ distinguishes between empathy and sympathy, an important 
distinction often overlooked; "In empathy we focus our attention on the feelings and the situation of the other person.... When we sympathize, we are preoccupied with the assumed duality or the parallel between our own feelings and the feelings of others." The need to differentiate empathy from identification is also suggested by Greenson ${ }^{9}$ with empathy viewed as a kind of emotional knowing. The emphasis seems to be on an emotional level of reaction to the object based on processes developmentally prior to the operation of the identification mechanism. This view is clearly advanced by Sullivan ${ }^{36}$ in his discussion of empathy; he relates this process to the direct and immediate apprehension by the infant of the mood of the mother.

The basing of the empathic capacity upon the earliest form of object-relation, a relation which precedes the development of structured boundaries between the self and nonself, permits clear differentiation of this concept from that of inference. In contrast to the process of inference, where the affective element is significant mainly in the negative sense of a potentiality for distortion of the cognitive function, the empathic capacity is based upon and operates as a mode of comprehending in which the affective experience is primary. There is in the empathic act a temporary suspension of ego functions in favor of an immediate, precognitive experience of another's emotional state as one's own. This fusion of self and nonself is, in a sense, a regressive process, yet the link to cognitive control is not fully severed. The empathic experience emerges from a primitive mode of object relation but does not remain solely as a diffuse global feeling. It progresses through a cognitive filter which transforms affective experience into comprehension of the meaning of the experience in the object, in the self, and in the self-object interaction. The active use of the passive receptive aspect of empathy is implicit also in Flesher's" description of empathy as "sharing another person's feelings with the purpose of understanding him." In the light of the foregoing discussion, the following definition of empathy is offered. Empathy is a process of comprehending in which a temporary fusion of self-object boundaries, as in the earliest pattern of object relation, permits an immediate emotional apprehension of the affective experience of another, this sensing being used by the cognitive functions to gain understanding of the other. ${ }^{10}$

The empirical study of the construct empathy suffers from two major weaknesses: the definitional formulations offered are not specific enough, and the operationalization of such definitions does not allow for a sufficiently high level of construct validity. However, by adopting the new transpositional research strategy, one can expect to achieve a much higher level of construct validity by placing the operationalized behavior outside the clinical realm. ${ }^{12}$

The behavioral realm chosen for the study of empathy was the acquisition of nativelike pronunciation in a second language. ${ }^{15,37}$ Teachers of second languages have frequently made the observation that the ability to speak a new language authentically, to assimilate or approximate native-like pronunciation, cannot be totally accounted for by the learner's intelligence, motivation, or skill in language training, and it does not seem to be modified to any great extent by training or effort. ${ }^{4}$ In examining the literation on second language acquisition, one fact emerges: namely, the uniqueness of accent or pronunciation as a feature of language performance.

In the classical literature on primary language acquisition, accent is largely ignored. We know, for example, that intonation contours are apparent as early as 5 months of age, and this is in fact the first discernable feature of natural language. ${ }^{22}$ At approximately 11-12 months of age actual speech begins with the learning of words, and it 
appears that syntax acquisition continues until the child is at least $5 \frac{1}{2} .{ }^{27}$ Pronunciation, however, unlike grammar or vocabulary has not been dated. It is tempting to speculate that pronunciation in terms of regional accent is achieved with the utterance of the first word. At the very least, one could say that even the most immature speaker can readily be identified as a native; there is no confusion on that point.

The gap between pronunciation ability and other language skills is dramatically underlined by the general observation that at puberty, second language pronunciation skills are drastically reduced if not irrevocably lost. ${ }^{2,22}$ It appears that beyond this period a truly native pronunciation in a second language is almost impossible to achieve. At the same time there is ample evidence that there is not an equal amount of loss of general language learning ability.

Scovel ${ }^{34}$ has made a case for the relationship of loss of pronunciation ability to the completion of lateralization of speech function which is achieved at approximately age 13. A number of researchers have commented on the special features of adolescent language learning which could, beyond any biological factors, help account for differences between adolescent and child language learning. ${ }^{3,32}$

Neither of the above approaches is entirely satisfactory. Even considering that, at puberty, the central processes involved in speech function have matured, we are left with the fact that there are enormous individual differences in pronunciation ability in young adults. Furthermore, while we would acknowledge that second language learning at puberty is particularly difficult, there is a more general problem which concerns the assessment of second language learning in the formal school setting.

It has been pointed out that language learning becomes an increasingly more complex academic task which in dramatic comparison with first language learning is less expressive, less action-oriented, and less affectively charged. ${ }^{3,5,34}$ Second language learning in the public schools contrasted with first language learning in a less critical task in terms of total self expression. It is therefore dangerous to make statements about language learning ability based solely on assessment in the public schools. This is particularly true when dealing with pronunciation ability. Pronunciation is probably the least stressed feature of second language performance, and students, at least below the college level, are rarely taught by a native speaker.

Returning once more to the frequently cited phenomenon of depression of second language pronunciation ability in puberty, as it was pointed out above, one of these issues is the problem of individual differences. Another critical issue concerns the course of development of second language pronunciation ability. It is simply not enough to say that pronunciation ability diminishes at puberty or that children in general demonstrate greater ability in second language pronunciation than adults. It is essential to ascertain the dimensions of pronunciation ability at each level. Too often language studies with children do not include very young children, ${ }^{17}$ who represent a theoretically critical sample; while age related studies usually fail to include a sufficiently broad range of ages. ${ }^{21,28}$ Even where age range is adequate there may be added problems of lack of control for factors such as intelligence, socioeconomic status, education, etc. ${ }^{1}$

I would emphasize again that pronunciation ability appears to be a unique feature of second language learning in terms of fluctuations in this ability during development that do not entirely coincide with shifts in general language learning abilities. In order to document those fluctuations, noting in particular when they are maximal or minimal, it is essential to collect normative data on second language pronunciation ability 
by age level. It is only by analyzing this overall picture that we can begin to determine the extent to which the history of pronunciation ability is indeed unique and to speculate on the possible causes for this uniqueness.

As I have stated elsewhere ${ }^{16}$ language behavior is a unique and complex attribute of man, not only in the evolutionary sense, but in the developmental psychological history of each individual. Language behavior arises and evolves within the context of a more general psychological growth. It is reasonable to speculate that even certain structural aspects of language are in part shaped by and express the broader personality context from which they have emerged. Thus it is only by regarding pronunciation ability within this context that we may begin to understand not only the course of its development but the processes involved in that development.

The degree to which the individual engages himself in the learning of a foreign language is, I believe, a joint function of flexibility of psychic processes and the particular aspect or aspects of language learning that emphasized the external demands. I would theorize that among the four major aspects of language behavior: reading, writing, understanding, and speaking, psychologically the most demanding is speaking. Speaking a foreign language entails the radical operation of learning and manipulating a new grammar, syntax, and vocabulary and, at the extreme limits of proficiency, modifying one of the basic modes of identification by the self and others, the way we sound. I would say then that of the skills involved in correctly speaking a foreign language, authenticity of pronunciation is the most psychologically critical. I propose, in fact, that authenticity of pronunciation is not a capricious, strangely illusive, nonessential dimension of second language ability, but rather the key to the extent to which the individual is psychologically capable of stepping into a new system of communication.

By looking at authenticity of pronunciation of a second language developmentally and from the point of view of psychoanalytic ego psychology, it becomes possible to sec in it an expression of the same processes that first aroused our interest in the clinical interactional situation.

At the risk of committing the original sin of producing one more vaguely defined concept, I wish to introduce a new construct "language ego." In a manner similar to the concept of body ego, language ego too, is conceived as a maturational concept. The original Freudian notion of body ego (an acknowledgment of the biolugical basis of all development) was expanded by Hartmann to emphasize "the influence of body image, particularly on the differentiation of the self from the object world." ${ }^{18}$ Body ego thus, refers to a self-representation with physical outlines and firm boundaries. Permeability in these boundaries (as in the case of the gifted pilot or race-car driver) is individually determined and will depend on crucial events in early life.

It can be argued that language represents a later and higher level of self-representation. In this view, language and speech achieve and express an advanced level of integration between internal and external components of self-representation. An integration is achieved between thought and speech, between ego and body ego. In a way, language and speech become the highest form of ego integration.

Language, too, will have, similar to the body ego, its physical outlines and firm boundaries. Grammar and syntax are the solid structures on which speech hangs, lexis the flesh that gives it body, and pronunciation its very core. Pronunciation is the most salient aspect of the language ego, the hardest to penetrate (to acquire in a new 
language), the most difficult to lose (in one's own). The proposition that pronunciation is indeed the very core of the language ego finds dramatic support in the observation that contrary to vocabulary, syntax, and grammar, which are all subject to serious impairment in the different speech dysfunctions, pronunciation seems to be immune to such loss. However distorted his speech may become, a native speaker will never be mistaken for a foreigner. Pronunciation is the most critical and most valuable contribution of the language ego to self-representation.

The permeability of these language boundaries, specifically the flexibility of the pronunciation boundaries is developmentally and genetically (in the psychoanalytic sense) determined. That is to say that pronunciation permeability will correspond to stages in the development of the ego; in the early formative stages of general ego development greater flexibility is allowed. Just as other ego functions (and self representation) are in a state of flux, so will the promunciation barrier fluctuate. In other words, a child can assimilate native-like speech in any language. Once ego development is concluded, however, that flexibility will be sharply restricted forever. It will be well-nigh impossible for an adult to learn any new language with authentic pronunciation. Thus, the levels of permeability of the language ego correspond to stages in the ego development of the individual.

Individual variations among adults in the degree of approximation of nativelike authenticity, in levels of permeability of the language ego are genetically determined. Object-relations capacity, as in empathy, will be a major determinant. Writing on this topic some time ago, we have suggested that:

In the earliest mother-child relationship, prior to stable establishment of separate self boundaries by the infant, the primary pattern of interaction is based on affective fusion. Diffuseness of self boundaries sensitizes the infant to changes in the quality and intensity of emotional states in those close to him. ${ }^{36}$ This sensitivity to expressive changes appears to be the prerequisite of empathic skill, a skill whose further development is dependent upon the quality of continuing interpersonal experiences during the developmental process. The sensitivity and empathic capacity existing in the affective relation to the mother may well be the vehicle through which original pronunciation authenticity is acquired and, by extension, may enhance the conditions favorable to later novel inclusions pertinent to second language authenticity. There is evidence that authentic replication of fragments of intonation contours begins to develop as early as four months of age. ${ }^{38}$ Very young infants have been shown to be highly responsive in modifying their behavior, including vocalization, in reaction to changes in interpersonal stimulation. Such stimulus patterns as smiling, body contact, and the voice of the mother can act as reinforcers in shaping infant behavior. ${ }^{31}$ The affective in teraction with the mother is a kind of reinforcement matrix within which the child learns the sounds of his language. ${ }^{29}$ A survey of research on the effects of early environment on oral language development, reported by May, ${ }^{25}$ points to the importance of a close and emotionally positive mother-infant relationship for the child's ability to assimilate correct speech habits and to speak accurately, ${ }^{16}$

In conclusion, I would say that second language acquisition in all of its dimensions demands that the individual, to a certain extent, incorporate a new identity. The first step in the completion of this process is pronunciation. Since pronunciation appears to be the feature of language behavior most resistant to change it can be assumed also to be the most critical to the individual's identity. Thus, individual differences in the ability to approximate native-like pronunciation should reflect individual differences in the flexibility of psychic processes, or more specifically, in the empathic capacity. Going beyond the basic hypothesis, I would submit that empathic capacity is related not only to pronunciation ability, but also, in yet to be determined ways, to the 
over-all capacity to acquire a second language, i.e., to incorporate a new system of communication.

Based on the above considerations it is now possible to embark on a study of high constructs, on an empirical investigation of basic ego-psychological issues such as empathy, or flexibility of psychic processes, in general, using second language as the transposed realm of empirically researchable behavior, conforming to the methodological requirements posited earlier.

The research strategy I have adopted for this major effort has a three-pronged approach. It consists of the empirical study of the approximation of native-like pronunciation in a second language in three different dimensions: as developmental stages, as stable differences in adults, and as experimentally induced behaviors.

The major thrust of our research to this date has been in two directions: to relate individual differences in pronunciation permeability to the underlying psychological determinants and to induce changes in pronunciation permeability in a controlled experiment so that the induced and measured changes can be unequivocally linked to the hypothesized psychological determinants. I would like first to report briefly on some of the results obtained in these efforts; the third dimension, that of establishing developmental norms, i.e., changes across age groups, is at this writing in its initial stage and no results are available yet.

In a pilot study, initiated in 1967, we have examined the relationship between success in speaking a second language (French) authentically and a variety of personality dimensions. ${ }^{15}$ This study included the first use of the micro-momentary expressions (MME) procedure for the measurement of empathy. It was hypothesized that an ability to perceive minimal interpersonal cues, standardized in this case by use of selected film strips shown at different speeds, would be related to individual differences in empathic capacity. A significant relation (rank order correlation of +0.60 ) was found between this measure and pronunciation proficiency.

A second study ${ }^{37}$ introduced refinements in the MME apparatus, an alternate projective measure of empathy and four independent measures of the facility of Englishspeaking subjects in learning authentically to speak a limited Japanese vocabulary. We have been most specifically concerned with the methodology of assessing authentic pronunciation in a second language. The outline of the procedure developed by us is as follows. A script composed of approximately 20 sentences in the desired language is prepared, each sentence having from one to three predetermined points of pronunciation difficulty. A high-quality tape recording is then made as a female native speaker of the language enunciates each of the sentences in a natural style, a space of approximately two and a half times the length of each utterance is left between sentences. In the testing phase, subjects are asked to repeat each sentence, reproducing the words exactly as they sounded. A printed copy of the script is available during the procedure in order to minimize effects of short-term memory and lexical and grammatical familiarity. A two-track recording is made during the test, with the stimuli recorded on one track and the subject's responses recorded on the other. In the final step, three native speakers of the language working independently listen to the subject's tapes. Each predetermined critical point of pronunciation is evaluated on a fixed scale, and ratings of the three judges are summed. Interjudge reliability, as measured by Pearson correlation coefficient, of these ratings ranged from 0.71 to 0.89 with a mean value of 0.81 .

The results obtained in this study indicated that the MME and TAT scores combined 
with a measure of verbal intelligence accounted for more than half of the variance in language (pronunciation) performance, as indicated by a multiple correlation of $R=+0.72$.

Highly significant as the results of these two laboratory studies were, both in terms of basic psychological research and applied linguistic research, we felt the need for a large-scale replication using intensive learning situations and truly representative samples. Such a large-scale study became possible through a research contract with the Defense Language Institute in 1970.

Beginning in July 1970 and through June 1971 we have been able to collect complete pretest and performance data on close to 500 people. Subjects in this sample were studying one of five different languages: Russian, Chinese-Mandarin, Spanish, Thai, and Japanese. All members of the group were serving in the Armed Forces of the United States. They represent a cross-section of the population in terms of regional origin and, in general, constitute a sample far more representative of the general population than the usual college population reported on in psychological studies. The results of this large-scale replication confirmed the findings of the earlier study. A multiple correlation of $\mathrm{R}=+0.69$ was found between pronunciation performance and the combined measures accounting for $49 \%$ of the variance.

It will be recalled that, guided by a theoretical model developed in successive publications, ${ }^{10-14}$ we hypothesized that individual variations in the ability to approximate native-like pronunciation in a second language are, in part determined by certain psychological variables best subsumed under the construct empathy, or more broadly, the concept of permeability of ego boundaries. These variables can be investigated in three manifestations: as stable characteristics of adults, as milestones in the growth curve in the course of development, and as experimentally induced behaviors.

In our program dealing with the third of these propositions, i.e., the experimental induction of behaviors, we have planned to study the effects of different agents (e.g., alcohol, drugs, hypnosis) on the target behavior. One such study, just completed, has attempted to achieve lowering of inhibitions, or enhancing of the permeability of ego boundaries by means of controlled ingestion of alcohol.

The psychology of alcohol consumption is still far from able to explain why people consume it in small amounts. Various theories have been proposed to explain alcoholism, ${ }^{26}$ but they are not too helpful in explaining the behavior of social drinkers. The rescarch litcrature on the effects of alcohol shows that alcohol impairs functioning at all levels. Yet, as Kalin, McClelland, and Kahn ${ }^{19}$ stated: "... it is hard to believe that people drink in order to think, talk, or act in an uncoordinated, inefficient way."

The positive aspects of social drinking have been neglected, but these are the ones that people report about most often. Straus and Bacon ${ }^{35}$ reported that college students mentioned positive reasons for drinking ("to get high") as well as ones involving reduction of anxiety ("not to be shy"). Kalin, McClelland, and Kahn ${ }^{19}$ studied the early, "positive" stage of alcoholic intoxication and suggested that alcohol diminishes the need for logical and affective consistency characteristic of every day dealings with reality. A similar idea was expressed by Levy ${ }^{23}$ who stated that "alcohol diminished the need of the ego for synthesis, for logical consistency, for unambivalence. ${ }^{11}$

"Lowering of inhibitions" (or behaviors described as such) may be conceptualized as the result of an alteration of particular, internal processes. For example, mild vertigo, due to alcohol consumption can be seen as stemming from a reduced efficiency in the 
functions regulating equilibrium. Similarly, slips of the tongue, which often occur after alcohol consumption, appear to be related to changes to intrapsychic equilibrium, i.e., certain thoughts which were previously kept out of conscious awareness suddenly and involuntarily find a linguistic outlet.

These examples are but two specific illustrations of the myriad of internal processes called "ego functions." Some others include eye-hand coordination, accurate perception of reality, logical thought, etc.

A much more complex ego function, whose fluctuations are not as easily recognized in specific behaviors as those mentioned above, is the ability to maintain one's identity separate from others. It has been hypothesized ${ }^{12}$ that the capacity to partially and temporarily give up this "separateness" is largely responsible for the phenomenon known as empathy. Carried to an extreme, giving up one's separateness results in the loss of identity found in various psychotic conditions.

The present study focused on the effects of alcohol consumption upon the ability to partially and temporarily give up the separateness of identity. It was hypothesized that this ability (often called permeability of ego boundaries) is affected by alcohol consumption just as many more obvious ego functions are.

Our earlier studies have strongly suggested that the empathic process deriving from the ability to partially and temporarily suspend the functions that maintain one's separateness from others (usually called ego boundaries) is manifested in an increased capacity to authentically pronounce a foreign language. ${ }^{15,37}$

The idea that certain inhibitions are lowered by drugs (including alcohol) is widespread and properly documented. Thus, lowering of inhibitions can be seen as the operational definition of permeability of ego boundaries; furthermore, the experimental induction of such behavior can be seen as the experimental manipulation of the underlying processes themselves.

The purpose of the study was to examine the effects of a small amount of alcohol on the ability of college students to pronounce words and phrases in a foreign and totally unknown language (Thai). We hypothesized that the effect will be an improvement in the ability to approximate authentic pronunciation as compared to a control group who will not consume alcohol (but a placebo designed to simulate alcohol).

Eighty-seven University of Michigan students served as subjects for the pilot experiment. All were over 21 years of age and were informed in advance only that the experiment would involve responses to an alcoholic beverage. The results of this study are highly illuminating. The hypothesis that the experimentally induced lowering of inhibitions or enhancing of the permeability of ego boundaries will lead to a corresponding enhancement of the pronunciation permeability was conclusively confirmed $(\mathrm{t}=4.47 ; \mathrm{a} \leqslant 0.01)$.

This finding is all the more interesting in light of the fact that overall mental functioning, (cognitive, psychomotor, memory, i.e., integrated ego functioning) as measured by the Digit Symbol Test is adversely affected by the same condition. In other words, pronunciation permeability is apparently critically influenced by a psychological variable that can be successfully isolated out of the total web of ego functioning. Taken together with results of our investigation of stable differences in adults, the study of pronunciation permeability thus enables us to reduce the concept of empathy (or permeability of ego boundaries) from the level of a high construct to that of a low construct by making variations in the observed overt behavior (pronunciation) explicable only through the use of that very construct. 
In terms of methodological considerations alone, the successful reduction of a high construct to the level of a low construct is a major gain in itself. (A detailed discussion of all the implications and ramifications of this study will be offered in a separate publication to follow the completion of two complementary experiments.)

Our efforts, experimentally to relate psychoanalytic concepts such as ego development and ego boundaries to cognitive and biological concepts, using pronunciation permeability in a second language as their index have the goal of being paradigmatic.

As I have stated elsewhere, the relevance and success of scientific inquiry depend, in the main, on three crucial steps: (1) the recognition or discovery of significant problem areas that need and can be explored; (2) the formulation of clear and appropriate questions in terms that lend themselves to empirical investigation in such a way that the ensuing data will have relevance to the questions posed; and (3) the use of appropriate techniques of analysis, both statistical and conceptual, for the evaluation of the information gathered. ${ }^{13}$

It is my hope that the development of transpositional research as a strategy, and our subsequent work based on it, bring us a step closer to our professed ideals, to our desire to understand and to explain human behavior in its infinite complexity, yet essential lawfulness, and to do so in the public domain, and in a manner that is demonstrable, reproducible, and accessible to all.

Fig. 1

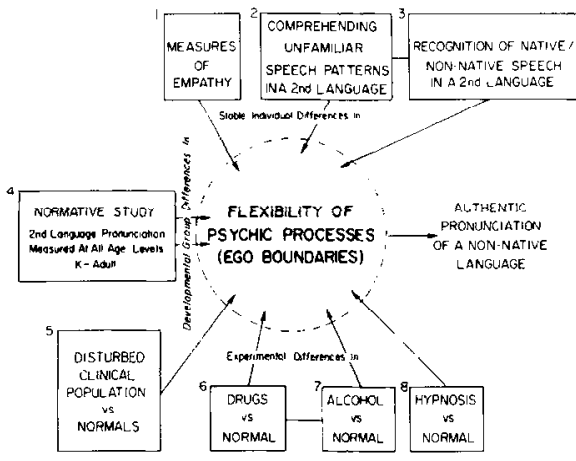

\section{ACKNOWLEDGMENT}

The present paper is the culmination, in a theoretical exposition of 7 years of labor. Beginning with the intuition paper ${ }^{14}$ and through a number of publications and up to the half dozen or so research papers currently in various stages of writing, this has been and continues to be a singleminded effort. Clearly, whatever fruits this effort has borne are not mine alone. Over the years colleagues, students, and associates have participated in one or another aspect of this endeavor. I wish to list them all, in recognition and gratitude, introducing their names with the classical Hebrew saying: "From all my teachers I have learned, including my students:" Benjamin BeitHallahmi, Robert K. Bolin, Lewis A. Bosworth, Marvin A. Brandwin, Robert C. L. Brannon, John C. Catford, James Dew, Cecelia Y. Dull, Charles E. Dutton, Robert Garwood, John Hartmann, Ronna Hoy, Neil Kalter, Harlan L. Lane, the late Bernard Meer, Tom Scovel, and Linda Taylor.

\section{REFERENCES}

1. Asher, J. J., and Garcia, R.: The optimal age to gain a foreign language. Mod. Lang. $J$., $53: 334,1969$.

2. Ausubel, D. P.: Adults versus children in second language learning: psychological consideration. Mod. Lang. J. 48:420, 1964.
3. Carroll, J. B.: Contributions of psychological theory and educational research to the teaching of foreign language. Mod. Lang. $J$. 49:273, 1965.

4. -, Clark, J. L., Edwards, T. M., and Handrick, F. A.: The foreign language attainments 
of language majors in the senior year: a survey conducted in U.S. colleges and universities. Final report for contract OE-4-14-048 with the U.S. Otfice of Education, Department of Health, Education, and Welfare, 1967.

5. Ervin, S. M.: Language development. In Hoffman, M. L., and Hoffman, L. W. (Eds.), Review of Child Development Research, Vol. 2. 1966, p. 55.

6. Fenichel, O.: The Psychoanalytic Theory of Neurosis. New York, Norton, 1945.

7. Flesher, V.: On empathy, intuition and countertransference. 1963. Unpublished.

8. Freud, S.: Group Psychology and the Analysis of the Ego. New York, Liveright, 1949.

9. Greenson, R.: Empathy and its vicissitudes. Int. J. Psychoanal. 41:425, 1960.

10. Guiora, A. Z.: On Clinical diagnosis and prediction, Psychol. Rep. 17:779, 1965.

11. - : The clinical process and its inquiry (in Hebrew). Megamot, 17:345, 1971.

12. - : Toward a systematic study of empathy. Compr. Psychiat. 8:375, 1967.

13. - : Transpositional research in the clinical process. Compr. Psychiat. 11:531, 1970.

14. -, Bolin, R., Dutton, C., and Meer, R.: Intuition: a preliminary statement, Psychiat. Quart. Suppl. 39:110, 1965.

15. -, Lane, H. L., and Bosworth, L. A.: An exploration of some personality variables in authentic pronunciation of a second language. In Lane, H. L., and Zale, E. M. (Eds.): Studies in Language and Language Behavior, Vol. 4. 1967 , p. 261.

16. -, Taylor, L. C., and Brandwin, M. A.: A contribution to the psychology of second language behavior. In Proceedings of the Sixteenth International Congress of Applied Psychology, Amsterdam, Swets and Zeitlinger, 1969, p. 585.

17. Halladay, L. I.: A study of the effect of age on achievement in adults studying English in an intensive course. Unpublished doctoral dissertation, The University of Michigan, 1970.

18. Hartmann, H. Essays on Ego-Psychology - Selected Problems in Psychoanalytic Theory. New York, International Universities, 1964, p. 346.

19. Kalin, R., McClelland, D. C., and Kahn, M.: The effects of male social drinking on fantasy. J. Personality soc. psychol. 1:441, 1965 .

20. Katz, R.: Empathy: Its Nature and Uses. New York, Free Press of Glencoe, 1963, p. 8.

21. Lambert, W. E., and MacNamara, J.: Cog- nitive consequences of following a first grade curriculum in a second language. J. Educ. Psychol. 60:85, 1969.

22. Lenneberg, E. H.: Biological Foundations of Language. New York, Wiley Sons, 1967, p. 279.

23. Levy, R. I.: The psychodynamic functions of alcohol. Quart. J. Stud. Alcohol. 19:649, 1958 .

24. Loewenstein, R. M.: Christians and Jews: a Psychoanalytic Study, New York, International Universities, 1951.

25. May, F.: The effects of environment on oral language development. Elem. English 43:587, 1960.

26. McCord W., and Mccord, J.: Origins of Alcoholism. Stanford, Stanford University Press, 1960.

27. McNeill, D.: The development of language. In Musseh, P. (Ed.): Carmichael's Manual of Child Psychology, Vol 1. 1970, p. 961.

28. Menyuk, P.: Children's learning and reproduction of grammatical and nongrammatical phonological sequences. Child Develop., 39:849, 1968.

29. Mowrer, O. H.: Learning Theory and the Symbolic Pracess. New York, Wiley, 1960.

30. Reik, T.: Listening With the Third Ear. New York, Farrar, Straus \& Young, 1949, p. 468 .

31. Rheingold, H. L., Gewirtz, J. L., and Ross, H. W.: Social conditioning of vocalizations in the infant. J. Comp. Psysiol. Psychol. 52:68-73, 1959.

32. Rivers, W.: Teaching Foreign Language Skills. Chicago, University of Chicago Press, 1968.

33. Schafer, R.: Generative empathy in the treatment situation. Psychiat. Quart. 28:342$373,1959$.

34. Scovel, T.: Foreign accent, language acquisition, and cerebral dominance. Language Learning. 19, 245, 1969.

35. Straus, R., and Bacon, S. D.: Drinking in College. New Haven, Yale University Press, 1953.

36. Sullivan, H. S.: Modern Conceptions of Psychiatry. New York, William Allison White Foundation, 1947.

37. Taylor, L. L., Guiora, A. Z., Catford, J. C., and Lane, H. L.: The role of personality variables in second language behavior. Compr. Psychiat. 10:463, 1969.

38. Tonkova-Yampolskaya, R. V.: Initial stages of speech formation in children. $\mathrm{Zh}$. Vyssh. Nerv. Deiat. 351, 1966. 